\title{
Percepções de Mulheres em Tratamento do Câncer de Mama acerca do Impacto da Dança do Ventre no Otimismo e na Autoestima: Estudo MoveMama
}

doi: https://doi.org/10.32635/2176-9745.RBC.2021v67n2.1283

\author{
Perceptions of Women Undergoing Breast Cancer Treatment about the Impact of Belly Dancing on Optimism and Self-Esteem: \\ MoveMama Study \\ Percepciones de las Mujeres que se Someten a un Tratamiento contra el Cáncer de Mama Sobre el Impacto de la Danza \\ del Vientre en el Optimismo y la Autoestima: Estudio MoveMama
}

\author{
Lyara da Silva Moschen'; Vanessa Bellani Lyra²; Francine Stein³; Leonessa Boing ; Alcyane Marinho5; Adriana Coutinho de Azevedo \\ Guimarães ${ }^{6}$
}

\begin{abstract}
RESUMO
Introdução: Há uma crescente profusão de estudos que buscam relacionar ganhos trazidos pela atividade física ao tratamento adjuvante do câncer de mama. Objetivo: Investigar as percepções de otimismo e autoestima de mulheres em tratamento adjuvante de hormonioterapia do câncer de mama após intervençôes de dança do ventre. Método: Ensaio clínico randomizado, de abordagem mista (quali-quantitativo), com delineamento descritivo e exploratório, no qual foram randomizadas 14 mulheres para o grupo de intervenção da dança do ventre, com idade entre 40 e 71 anos, em tratamento clínico adjuvante de hormonioterapia no Centro de Pesquisas Oncológicas em uma cidade ao Sul do Brasil. Fez-se uso de um questionário aplicado em forma de entrevista individual, dividido em três partes: a) variáveis socioeconômicas; b) otimismo; c) autoestima. Também foram realizadas observaçôes sistemáticas e participativas durante a intervenção de dança do ventre, registradas em diário de campo e analisadas por meio da análise de discurso. Resultados: Constatou-se aumento na autoestima das mulheres no período pós-intervenção $(\mathrm{p}<0,001)$. Por sua vez, nas cinco mulheres que, além de finalizar a intervenção, participaram também da entrevista (pré e pós), os resultados quantitativos pouco alteraram. O estudo apresenta uma melhora clínica no otimismo com desvio-padrão de 4,6 após a intervenção, que pode ser interpretado como expressivo, ainda que não tenha impacto estatístico, considerando a utilização de uma metodologia mista no presente estudo. Conclusão: As percepções das mulheres deste estudo são positivas em relação à autoestima, confirmadas quali e quantitativamente, porém, apesar disso, o otimismo encontrou uma confirmaçáo discreta nos resultados quantitativos. Palavras-chave: Neoplasias da Mama; Autoimagem; Terapia através da Dança; Otimismo.
\end{abstract}

\section{ABSTRACT}

Introduction: There is a growing profusion of studies attempting to relate gains brought by physical activity to the adjuvant treatment of breast cancer. Objective: To investigate perceptions of optimism and self-esteem of women undergoing hormone therapy adjunctive treatment for breast cancer after belly dance interventions. Method: Randomized descriptive and exploratory design mixed approach (quali-quantitative) clinical trial where 14 women aged 40 to 71 years were randomized to belly dance intervention group in hormone therapy adjuvant clinical treatment at the Oncological Research Center in a Brazilian southern city. A questionnaire applied as individual interview divided in three parts was used: a) socioeconomic variables; b) optimism and c) self-esteem. Systematic and participatory observations during the belly dance intervention were completed and logged in a field diary and reviewed through discourse analysis. Results: It was possible to see an increase in women's self-esteem in the post-intervention period $(\mathrm{p}<0.001)$. On the other hand, for the five women who, in addition to finalizing the intervention, also participated of the interview (pre and post) the quantitative results have barely changed. The study shows a clinical improvement in optimism with standard deviation of 4.6 after the intervention, which can be interpreted as expressive, even though it has no statistical impact considering the use of a mixed methodology in the present study. Conclusion: Regarding self-esteem, women's perceptions confirmed qualitatively and quantitatively in this study are positive, however, despite this, the confirmation of quantitative results for optimism was modest. Key words: Breast Neoplasms; Self Concept; Dance Therapy; Optimism.

\section{RESUMEN}

Introducción: Existe una profusión creciente de estudios que buscan relacionar los beneficios aportados por la actividad física con el tratamiento adyuvante del cáncer de mama. Objetivo: Investigar cómo las percepciones de optimismo y autoestima de mujeres sometidas a un tratamiento adyuvante de la terapia hormonal del cáncer de mama después de las intervenciones de danza del vientre. Método: Ensayo clínico aleatorizado, de abordaje mixto (cuali-cuantitativo), con diseńo descriptivo y exploratorio, en el que se aleatorizaron 14 mujeres al grupo de intervención de danza del vientre de 40 a 71 ańos, en tratamiento clínico adyuvante de hormonoterapia en el Centro de Investigaciones Oncológicas, en una ciudad del Sur de Brasil. Se utilizó un cuestionario aplicado en forma de entrevista individual, dividido en tres partes: a) variables socioeconómicas; b) optimismo; c) autoestima. De forma sistemática y participativa durante la intervención de la danza del vientre, también se revisaron y analizaron las funciones en un diario de campo a través del análisis del discurso. Resultados: Fue posible ver un aumento en la autoestima de las mujeres en el período pos-intervención ( $\mathrm{p}<0,001)$. A su vez, en las cinco mujeres que, además de finalizar la intervención, también participaron de la entrevista (pre y post); los resultados cuantitativos han cambiado poco. El estudio muestra una mejoría clínica del optimismo con desviación estándar de 4,6 tras la intervención, lo que puede interpretarse como expresiva, aunque no tiene impacto estadístico considerando el uso de una metodología mixta en el presente estudio. Conclusión: Las percepciones de las mujeres en este estudio son positivas con relación a la autoestima, confirmadas cualitativa y cuantitativamente, sin embargo, a pesar de esto, el optimismo encontró una leve confirmación en los resultados cuantitativos. Palabras clave: Neoplasias de la Mama; Autoimagen; Terapia a traves de la Danza; Optimismo.

1-6Universidade do Estado de Santa Catarina (Udesc). Centro de Educação Física, Fisioterapia e Desportos (Cefid). Programa de Pós-Graduação em Ciências do Movimento Humano (PPGCMH). Florianópolis (SC), Brasil.

'E-mail: lyara.ar@gmail.com. Orcid iD: https://orcid.org/0000-0001-6491-1637

2E-mail: vanessablyra@gmail.com. Orcid iD: https://orcid.org/0000-0001-9653-2930

${ }^{3}$ E-mail: francinestein@unidavi.edu.br. Orcid iD: https://orcid.org/0000-0001-6501-0259

${ }^{4}$ E-mail: leonessaboing@gmail.com. Orcid iD: https://orcid.org/0000-0003-4978-9703

${ }^{5}$ E-mail: alcyane.marinho@hotmail.com. Orcid iD: https://orcid.org/0000-0002-2313-4031

6E-mail: adriana.guimaraes@udesc.br. Orcid iD: https://orcid.org/0000-0001-5167-2921

Endereço para correspondência: Vanessa Bellani Lyra. Rua Professor João José Cabral, 127 - Apto. 201 - Balneário. Florianópolis (SC), Brasil. CEP 88075-535. E-mail: vanessablyra@gmail.com 


\section{INTRODUÇÃO}

O câncer de mama é um dos mais comuns e uma das principais causas de mortes entre as mulheres no mundo. No Brasil, é o tipo de câncer mais frequente, depois do câncer de pele não melanoma, com estimativa de 66.280 novos casos para cada ano do biênio 2020-2022 e risco estimado de 61,61 casos a cada 100 mil mulheres ${ }^{1}$. Com incidência progressiva nos últimos anos, apresenta um elevado índice de morbimortalidade e mutilação ${ }^{2}$. Também, de acordo com dados já publicados, a incidência de novos casos de câncer de mama em mulheres no mundo foi de 2,1 milhôes em 2018, representando quase um caso a cada quatro casos de câncer ${ }^{3}$.

Mesmo com o avanço da ciência, as incertezas sobre o tratamento e seus efeitos colaterais ainda são grandes. A possibilidade da mastectomia total ou parcial pode acarretar muitas alteraçôes psicológicas, uma vez que a mama é um órgáo carregado de simbolismo referente à feminilidade, à maternidade, à sensualidade ${ }^{4} \mathrm{e}$ à própria identidade da mulher. Ao submeter-se à remoção total ou parcial da mama, a mulher passa por mudanças significativas que tangem a dimensōes físicas, emocionais e sociais ${ }^{2,5}$.

O diagnóstico e o tratamento podem ter efeitos devastadores na vida da pessoa que os recebe, sendo comum os sentimentos de baixa autoestima, imagem corporal negativa, medo de rejeição social e do cônjuge, e abalo na identidade feminina. Não há apenas o problema da doença em si, mas a fragilidade que as mulheres tendem a passar diante da estigmatizaçáo do câncer de mama e de seus efeitos biopsicossociais; o enfrentamento dos medos, frustraçôes, conflitos e instabilidade emocional ${ }^{6,7}$.

O equilíbrio psicológico é ameaçado por essas mudanças e tende a ser de identificação negativa ${ }^{8}$. A baixa autoestima está relacionada à ausência de afeto positivo que o indivíduo tem de si próprio, à falta de valorização que, consequentemente, é de relevância na interação com os outros, uma vez que sua condição de vida está arrolada com essa imagem de si. Diante desse cenário, de autorrejeição, além do tratamento tradicional, é preciso buscar novas formas que instiguem a mulher a ter uma percepçáo positiva de si, pertinente a um aumento da qualidade de vida, contemplando um estado emocional pleno que, mesmo desestabilizado, procura manter-se saudável, confiante, afirmando o seu valor positivo, elevando a capacidade e o desenvolvimento humano para viver com maior otimismo?.

Nessa perspectiva, acredita-se que a dança do ventre pode auxiliar na percepçáo sobre o corpo da mulher que propende ter baixa autoestima e falta de otimismo perante a vida e a doença. Carregada de simbolismos sobre feminilidade, existe um diálogo entre o corpo e a dança. É um processo constante na transformação de si e do entorno, pois une atividade física, expressão artística e convívio social, para além da configuração anatômica e biomecânica. A dança fomenta o entendimento do corpo simbólico, visto aqui como corpo feminino e cultural, atuando no resgate da feminilidade, suavidade e beleza, por meio dos movimentos expressivos e de consciência corporal, explorando, ainda, a confiança e a segurança das pacientes, ampliando o contato consigo mesma, de forma íntima e integral ${ }^{10}$.

Focando na relação do câncer de mama com os problemas biopsicossociais e os efeitos do tratamento não medicamentoso, este estudo tem como objetivo investigar as percepçóes de otimismo e autoestima de mulheres em tratamento adjuvante de hormonioterapia do câncer de mama, após intervençóes de dança do ventre.

\section{MÉTODO}

Ensaio clínico randomizado, de abordagem mista (qualitativo-quantitativo), de delineamento descritivo e exploratório, que faz parte de um projeto maior, o MoveMama, constituído por um ensaio clínico randomizado de três braços: a) intervenção de dança do ventre; b) intervenção de pilates solo; e c) grupo controle. Neste estudo, especificamente, foi avaliado o grupo de intervenção de dança do ventre.

O referido estudo foi aprovado pelos Comitês de Ética em Pesquisas com Seres Humanos da Universidade do Estado de Santa Catarina, sob o n. ${ }^{\circ}$ 2.252.288, e do Centro de Pesquisas Oncológicas (Cepon) nº 2.319.138, registrados na plataforma internacional de registro de ensaios clínicos "Clinical Trials.gov" (n. NCT03194997) e na plataforma nacional "Registro Brasileiro de Ensaios Clínicos" (identificador RBR-2ttf8m).

As participantes do estudo tinham entre 40 e 71 anos e foram diagnosticadas com câncer de mama no período de tratamento clínico adjuvante de hormonioterapia no Cepon em Florianópolis (SC), cidade ao Sul do Brasil. O estudo foi composto por 14 mulheres randomizadas para o grupo de intervenção da dança do ventre, que participaram da coleta pré e pós-intervenção, respondendo aos questionários. Destas 14, apenas cinco participaram das entrevistas, além de responderem aos questionários. As demais não puderam continuar no estudo em função de agravamento na doença, exames médicos, fisioterapia, problemas familiares, entre outros.

As mulheres selecionadas para participarem desta pesquisa atenderam aos critérios de inclusão: (1) faixa etária maior do que 18 anos; (2) estádios clínicos I a III do câncer de mama; (3) estar em tratamento adjuvante com 
hormonioterapia; e (4) receber a liberação do oncologista responsável para a prática de atividade física, bem como do Setor de Fisioterapia do Cepon. O critério de exclusão foi apresentar alguma limitação ortopédica ou neurológica que impedisse a prática de atividade física. As mulheres que aceitaram participar voluntariamente da pesquisa assinaram o Termo de Consentimento Livre e Esclarecido (TCLE) e o Termo de Consentimento para fotografias, vídeos e gravaçóes.

Conforme observado na Figura 1, os instrumentos de coleta de dados foram: um questionário (dividido em questóes sociodemográficas e clínicas) e dois instrumentos validados que foram aplicados em forma de entrevista individual. Foi utilizado ainda um roteiro de observaçáo participante, momento prático e relacional, no qual criou-se um elo de interaçáo entre a pesquisadora e os investigados ${ }^{11}$. A observação ocorreu de forma sistêmica, com o objetivo de perceber de que modo a dança do ventre foi desenvolvida, suas características (duração, recursos utilizados, metodologia), quem ministrou, as expressôes implícitas e explícitas, a linguagem que as mulheres utilizaram, as emoçôes percebidas antes, durante e depois da intervenção, e a aproximação delas com a ministrante, com o ambiente e com os demais que não fizeram parte do estudo.

Por fim, foi utilizado um diário de campo ${ }^{11}$ para registrar as questôes observadas nas intervençôes práticas e nas gravaçôes de áudio das entrevistas. Tratando-se de uma entrevista semiestruturada, existiu a possibilidade de a participante falar abertamente sobre o tema em questão, sem se deter às perguntas básicas feitas pela pesquisadora ${ }^{11}$, possibilitando também que esta não ficasse limitada ao roteiro preliminarmente definido. As variáveis do estudo foram: (1) sociodemográficas: idade, escolaridade, estado conjugal e nível econômico, conforme critério do Instituto Brasileiro de Geografia e Estatística (IBGE) ${ }^{12}$, que classifica a populaçáo por meio da renda familiar média mensal. As classes foram: classe A (acima de 20 salários-mínimos); classe B (10 a 20 salários-mínimos); classe C ( 4 a 10 salários-mínimos); classe $\mathrm{D}$ ( 2 a 4 salários-mínimos); e classe $\mathrm{E}$ (até 2 salários-mínimos). Tomou-se por base o salário-mínimo de 2018, no valor previsto de $\mathrm{R}$ \$ 954,00; (2) variáveis clínicas: tratamento atual, tipo de protocolo de tratamento, características da intervenção cirúrgica se conservadora/radical, reconstrução mamária tardia/imediata/náo realizaçáo, presença de linfedema (autorrelato), tratamento de fisioterapia.

Com relação à autoestima, utilizou-se a escala de autoestima (EAR) de Rosenberg ${ }^{13}$. Esta foi validada para a população com câncer ${ }^{14} \mathrm{e}$, no Brasil, validada ${ }^{15} \mathrm{e}$ revisada ${ }^{16}$. É uma medida unidimensional composta por dez afirmaçóes referentes a um conjunto de sentimentos de autoestima e autoaceitação que determinam a autoestima global. A pontuação varia de dez a 40 pontos, segundo o seguinte padrão: (A1) autoestima satisfatória ou alta: escore maior do que 31 pontos; (A2) autoestima média: escore entre 21 e 30 pontos; (A3) autoestima insatisfatória ou baixa: escore inferior a 20 pontos. Ou seja, quanto maior o valor atingido pela mulher na escala, melhor é considerada a sua autoestima ${ }^{13}$.

No que diz respeito ao otimismo, foi classificado por meio do instrumento de Teste de Orientação da Vida (TOV-R), validado no Brasil, sendo composto por dez itens. Tal escala investiga a concepçáo de otimismo e a

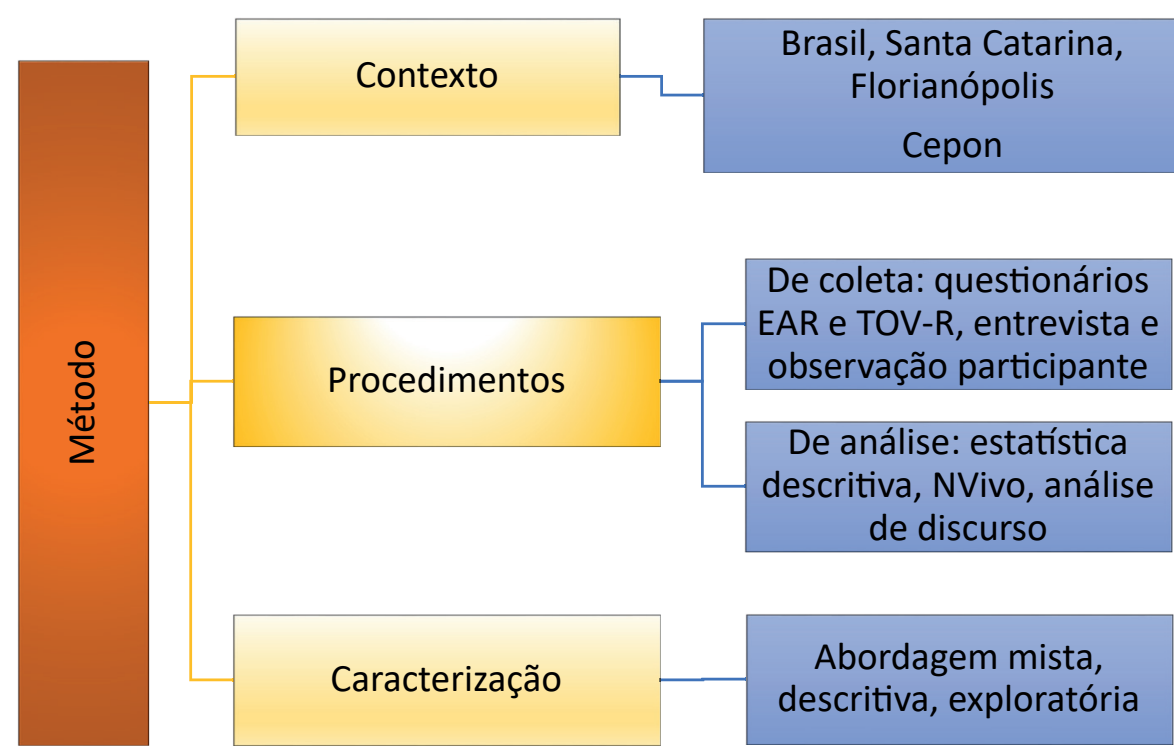

Figura 1. Fluxograma de detalhamento dos métodos 
compreensão dos pacientes em relação às expectativas com eventos futuros. E Estabelece que quanto maior a pontuação maior o otimismo disposicional do participante $^{17}$.

A coleta de dados ocorreu em três momentos. A primeira etapa aconteceu nas instalaçóes do Centro de Educação Física, Fisioterapia e Desportos (Cefid) da Universidade do Estado de Santa Catarina (Udesc), em maio de 2018, com a aplicaçáo dos questionários EAR, TOV-R e de variáveis socioeconômicas, mediante agendamento com a equipe de pesquisadoras do Laboratório de Pesquisa em Lazer e Atividade Física (LAPLAF) do Conselho Nacional de Desenvolvimento Científico e Tecnológico (CNPq) (coleta pré-intervenção). De julho a setembro de 2018, foi aplicada a entrevista semiestruturada, de forma individual, com agendamento prévio para cada participante, no Cepon. No terceiro momento, após o término da intervenção de dança do ventre, foi realizada uma nova entrevista semiestruturada individual com agendamento prévio para a segunda aplicação dos questionários EAR, TOV-R e variáveis socioeconômicas (coleta pós-intervenção).

Durante o período da intervenção, as observaçóes ocorreram de forma sistemática e participativa. No primeiro momento, com as variáveis definidas (autoestima e otimismo), a pesquisadora principal se apresentou ao grupo, informando que anotaria fatos provenientes das intervençôes. No segundo momento, esta se inseriu no ambiente e participou ativamente das intervençôes de dança do ventre, o que possibilitou uma aproximação das participantes do estudo, ampliando laços de confiança. Com a sua presença efetiva nas intervençóes, foi possível notar que o comportamento das mulheres observadas se tornou mais espontâneo, permitindo a ela transitar nos dois formatos de observação, sistêmica e participativa, com maior naturalidade.

\section{Protocolo de interVEnção da dança do VEnTRE}

A intervenção de dança do ventre teve 48 sessões, dispostas em 16 semanas, com uma frequência de três vezes por semana e duração de 60 minutos por sessão matinal, de acordo o protocolo ${ }^{18}$. As aulas foram ministradas no espaço de convivência externa, localizado no $1^{\circ}$ andar da Unidade de Internação do Cepon por duas profissionais da área da saúde, uma da Educação Física e outra da Fisioterapia, ambas vinculadas ao LAPLAF/CNPq. A frequência mínima exigida foi de $75 \%$ durante o período de intervenção para esse grupo, dada a importância da continuidade para atingir os benefícios providos pela prática regular do exercício. Assim, as pacientes participaram de um mínimo de 36 sessóes das 48 oferecidas para serem incluídas no estudo. Ao término das 16 semanas de intervenção, as mulheres receberam uma cartilha educativa sobre o câncer de mama, atividade física de intensidade leve e prevenção do linfedema, com o objetivo de estimular a continuidade da prática de atividade física após o término da intervençâo.

Foi utilizado o pacote estatístico SPSS - IBM, versão 20.0. Primeiramente, foi realizada a estatística descritiva (frequência simples, média, desvio-padrão) e, posteriormente, o cálculo da normalidade por meio do teste de Kolmogorov-Smirnov para escolha dos testes estatísticos. Para comparar os períodos pré e pós-intervenção, na variável autoestima, utilizou-se o teste t pareado; para verificar o otimismo, utilizou-se o teste de Wilcoxon. Nível de significância adotado de 5\%.

Para a organização dos dados qualitativos, foi utilizado o Software NVivo 12.0, que gerou as categorias de análise. Posteriormente, os dados foram analisados seguindo elementos da técnica de Análise de Discurso ${ }^{19}$. Essa técnica pertence a uma área da linguística que tem como objeto de estudo a palavra em movimento, que produz sentido enquanto prática. Também se procura entender não só a palavra, mas o contexto social, o espaço em que ocorre o discurso e seus efeitos de sentidos, compreendendo essa análise como "[...] um processo de significação no qual estão presentes a língua e a história, em suas materialidades, e o sujeito, devidamente interpelado pela ideologia ${ }^{19 "}$. Deste modo, o discurso náo pode ser qualificado apenas como difusor de informaçóes, pois o contexto histórico-social e os interlocutores são decisivos para a produção dos sentidos.

\section{RESULTADOS}

As mulheres participantes do estudo têm, em sua maioria, as seguintes características sociodemográficas e clínicas: ensino médio (57\%), solteira (50\%), profissão antes da cirurgia (92\%), pós-cirurgia, aposentada $(35,7 \%)$, e pertencentes à classe $\mathrm{E}(42,9 \%)$. Apresentaram incontinência urinária $(57,1 \%)$, menopausa $(71,4 \%)$, mastectomia conservadora $(78,6 \%)$, lado direito da cirurgia $(57,1 \%)$, esvaziamento axilar $(42,95)$, sem linfedema $(87,5 \%)$, sem cirurgia de reconstrução $(78,6 \%)$, tratamento atual com hormonioterapia $(85,7 \%)$ e não realizam fisioterapia $(71,4 \%)$.

$\mathrm{Na}$ Tabela 1, podem ser observadas as variáveis de autoestima e otimismo nos períodos pré e pós-intervenção de 14 participantes, mostrando diferença significativa na autoestima $(\mathrm{p}<0,001)$ no período pós-intervenção.

$\mathrm{Na}$ Tabela 2, são apresentadas as variáveis de autoestima e otimismo das cinco participantes que realizaram a intervenção da dança do ventre, bem como a coleta pré e pós e, posteriormente, a entrevista de forma qualitativa pré e pós-intervenção. Os dados mostram 
pouca variação entre os períodos pré e pós-intervenção dessas cinco participantes.

No Quadro 1, são apresentadas as categorias, as subcategorias, os indicadores e as unidades de contexto, extraídos dos discursos das participantes que realizaram as entrevistas pré e pós-coleta $(n=5)$, organizados com auxílio do Software NVivo, versão 12.0.

\section{RELAÇÃO E VIVÊNCIA COM A DANÇA DO VENTRE}

Algumas mulheres do estudo já haviam tido contato prévio com a prática de atividade física antes do diagnóstico do câncer de mama, por meio de modalidades como lutas, musculação, ciclismo, handebol e corrida, porém, com a dança do ventre, foi o primeiro contato para a maioria delas. Segundo as participantes, tal vivência trouxe mudanças, como ilustram algumas falas:
Eu era muito endurecida e agora estou desabrochando. A dança sacode os nossos pedaços né? Nos leva a nos abrir, abrir tanto a mente quanto o corpo. Eu gosto muito assim (Participante B).

A relação com a diminuição das dores corporais ficou evidente na fala da participante $B$, quando esta sugere que a prática regular da dança do ventre foi uma aliada importante na reestruturação de sua forma de pensar e agir corporalmente:

Incrível, eu não conseguia pegar um copo, parecia que era muito pesado, eu não conseguia e agora, com a dança, eu estou me cuidando e fazendo muito mais coisas com a mão esquerda e eu até estou me esquecendo da dor. A dança entrou na minha vida assim, com uma melhora incrível, é muito bom.

Tabela 1. Comparação entre a pré e a pós-intervenção das participantes do estudo quanto à autoestima e ao otimismo $(n=14)$

\begin{tabular}{lccc}
\multicolumn{1}{c}{ Variáveis } & $\begin{array}{c}\text { Período } \\
\text { pré-intervenção } \\
\overline{\mathbf{x}} \text { (desvio-padrão) }\end{array}$ & $\begin{array}{c}\text { Período } \\
\text { pós-intervenção } \\
\overline{\mathbf{x}} \text { (desvio-padrão) }\end{array}$ & Valor de p \\
\hline Autoestima & $29,5(4,2)$ & $36,0(3,7)$ & $<0,001^{*}$ \\
\hline Otimismo & $17,7(2,5)$ & $17,6(2,9)$ & $0,691^{* *}$ \\
\hline
\end{tabular}

Nota: $\mathrm{n}=14$, uma das participantes não realizou a coleta pós-intervenção.

(*) teste t pareado.

(**) teste de Wilcoxon.

Tabela 2. Comparação entre a pré e a pós-intervenção das participantes do estudo quanto à autoestima e ao otimismo. ( $\mathrm{n}=5)$

\begin{tabular}{|c|c|c|c|}
\hline Variáveis & $\begin{array}{c}\text { Período } \\
\text { pré-intervenção } \\
\overline{\mathbf{x}} \text { (desvio-padrão) }\end{array}$ & $\begin{array}{c}\text { Período } \\
\text { pós-intervenção } \\
\overline{\mathbf{x}} \text { (desvio-padrão) }\end{array}$ & Valor de p \\
\hline Autoestima & $32,0(1,8)$ & $36,6(4,0)$ & $0,017^{*}$ \\
\hline Otimismo & $17,0(1,8)$ & $18,0(4,6)$ & $0,684^{* *}$ \\
\hline
\end{tabular}

$\left({ }^{*}\right)$ teste t pareado.

${ }^{(* *)}$ teste de Wilcoxon.

Quadro 1. Organização das categorias, das subcategorias, dos indicadores e das unidades de contexto pela análise de discursos das participantes $(n=5)$

\begin{tabular}{|l|l|l|l|}
\hline \multicolumn{1}{|c|}{ Categorias } & \multicolumn{1}{|c|}{ Subcategorias } & \multicolumn{1}{c|}{ Indicadores } & Unidades de contexto \\
\hline $\begin{array}{l}\text { Relação e vivência } \\
\text { com a dança do } \\
\text { ventre }\end{array}$ & $\begin{array}{l}\text { Mudanças por meio da dança } \\
\text { Relação de prazer com a dança }\end{array}$ & $\begin{array}{l}\text { Diminuição das dores } \\
\text { Percepção positiva de si }\end{array}$ & $\begin{array}{l}\text { Sinto-me melhor } \\
\text { Mais alegre }\end{array}$ \\
\hline $\begin{array}{l}\text { Percepção das } \\
\text { mudanças físicas } \\
\text { e psicológicas por } \\
\text { meio da dança do } \\
\text { ventre }\end{array}$ & $\begin{array}{l}\text { Dança } \\
\text { Movimento } \\
\text { Leveza }\end{array}$ & $\begin{array}{l}\text { Estado emocional } \\
\text { Aceitação } \\
\text { Entendimento } \\
\text { Sexy } \\
\text { Linda } \\
\text { Maravilhosa }\end{array}$ & $\begin{array}{l}\text { Alegria } \\
\text { Vida } \\
\text { Sem dores } \\
\text { Leve }\end{array}$ \\
\hline $\begin{array}{l}\text { Convívio social e } \\
\text { identificação }\end{array}$ & $\begin{array}{l}\text { Família } \\
\text { Coletivo }\end{array}$ & $\begin{array}{l}\text { Identificação } \\
\text { Pertencimento }\end{array}$ & $\begin{array}{l}\text { Família } \\
\text { Grupo }\end{array}$ \\
\hline
\end{tabular}


Fez toda a diferença, é maravilhoso, me liberou, me trouxe uma paz que meu corpo começou a se reestruturar novamente (Participante B).

A dor também é lembrada na fala da participante $\mathrm{C}$, quando esta infere que a prática regular de dança do ventre contribuiu significativamente para a diminuição das dores corporais, inclusive, tornando possível a redução do uso de medicamentos específicos para esse fim. Para além, a participante também destaca a contribuição das aulas de dança do ventre na melhora percebida em sua autoestima:

Diminuíram muito as dores e estou tomando menos remédios também. De quatro comprimidos de codeína por dia, agora tomo dois por semana, a diferença é bem grande. Esse período [de aulas de dança do ventre] me ajudou na minha autoestima. Agora eu não me apego mais ao manequim, eu posso ser sexy (Participante C).

A participante A destaca o papel que as aulas de dança do ventre exerceram na manutenção de sua saúde mental, sobretudo, na construção de uma estrutura emocional mais forte e positiva:

Se não fosse a dança, eu teria entrado em depressão. A dança me ajudou bastante e eu aguentei firme, a dança muda bastante a vida da gente. Hoje estou mais forte, tenho mais força, hoje estou bem melhor (Participante A).

A mesma positividade pode ser encontrada na fala da participante $\mathrm{D}$, ao referir-se ao fato de perceber-se mais animada e alegre, quando do início da rotina de práticas. Não obstante, um sentido de "esperança” e "projeçôes futuras" podem também ser destacados nas falas das participantes D e E. Para ambas, a experiência de participar das aulas regulares de dança do ventre estimulou-as a "seguir em frente", alimentando em si uma visão positiva sobre si mesma, seu corpo e sua vida:

A dança me deixa mais alegre, eu me sinto uma princesa, eu me sinto muito bem, eu não tinha ânimo para nada, agora eu estou com planos de vida, de recomeçar a minha vida(...) (Participante D).

Eu só tenho alegria e felicidade, ao perceber meu corpo diferente, me sinto mais animada, entusiasmada, é um incentivo muito grande, estou mais feliz, com mais vontade de fazer as coisas, eu saio daqui radiante de alegria, feliz do coração, eu me sinto muito à vontade (Participante E).

\section{PeRCEPÇÃO dAS MUdANÇAS FÍSICAS E PSICOLÓGICAS}

(AUTOESTIMA E OTIMISMO) POR MEIO DA DANÇA DO VENTRE

Foram relatadas, algumas vezes, expressôes como dor, alegria, desânimo, felicidade, autoestima, satisfação e otimismo. As variaçóes de humor e de sentimentos se tornaram comuns e, sobretudo, constantes, haja visto que as mudanças foram encaradas de formas diversas. No entanto, o contato inicial com a descoberta do câncer foi, sobremaneira, a mudança mais desafiadora para a maioria delas. Tal situação é expressa na fala da participante D:

Quando eu soube, fiquei bem arrasada, pra mim o mundo tinha acabado (Participante D).

Apesar das dores e limitaçôes das habilidades físicas, percebe-se, nas falas, uma tentativa de manter a normalidade, demonstrando grande esforço pessoal de adaptar-se a esse momento de dificuldades:

A vida seguiu igual, não alterou nada, apesar da queda de cabelo, secura no nariz e perda das unhas, eu faço de conta que não é comigo (Participante E).

A confiança fomenta sentimentos de alegria o que pode desencadear maiores desejos de ação: "Eu queria me movimentar..." (Participante B). E pela ação do movimento no organismo, de forma sensível, perceber que:

Com a dança, eu fui alongando natural, o que mais me deixou maravilhada foi isso, que com os movimentos da dança do ventre, meu corpo, que estava todo paralisado foi voltando ao normal, eu sinto que estou melhorando sabe?, minha autoestima aumentou (Participante D).

Neste sentido, nota-se um sentimento positivo em relaçáo à percepção de si, do seu corpo e da sua atitude. O mesmo intuito, de positividade e resiliência, pode ser encontrado na fala da participante B:

A dança do ventre tem uma coisa legal, que sacode nossos pedaços e nos leva a nos abrir, abrir tanto a mente quanto as partes do nosso corpo. Vai quadril, vai braço, vai a mão... eu gosto muito, a professora sempre acha que estamos lindas, e ela diz: muito bem, lindas, isso mesmo... e nós estamos lá, fazendo tudo errado sabe? Mas ela diz com tanto carinho, que a gente acha que tá linda e maravilhosa.

A participante $\mathrm{D}$ relata que as aulas de dança do ventre exerceram uma melhora significativa no seu corpo, especificamente no que diz respeito à mobilidade de seu 
braço. A participante destaca que, após as intervenções, passou a conseguir realizar tarefas, para as quais anteriormente estava impossibilitada:

Eu não conseguia levantar o braço, fazia tudo com uma mão só, aí eu ficava muito cansada e sobrecarregava o outro lado, também náo conseguia dormir, me sentia muito mal [com a intervenção da dança do ventre], meu braço está esticando mais, a dor está diminuindo, eu até consigo passar um paninho no chão que eu não conseguia antes, estou sentindo tudo mudar para melhor.

\section{CONVÍVIO SOCIAL E IDENTIFICAÇÃO}

Esta categoria de análise evidencia a importância do convívio, do reconhecimento e do acolhimento entre as próprias participantes, além de salientar como esse contato apresentou um impacto positivo na sua trajetória de reestruturação emocional. A fala seguinte permite demonstrar essas questóes, de uma forma sintetizada e bem característica:

[...] eu gosto do coletivo, ficamos juntas, formamos uma família e nos auxiliamos, vemos que nossas dificuldades são parecidas e isso ajuda a continuar (Participante C).

O sentimento de pertencimento e apoio também pode ser percebido na fala de algumas participantes. O grupo de dança parece ter se tornado um ambiente com significados para além do ato de exercitar-se, beirando, inclusive, um ambiente familiar:

[...] além das minhas caminhadas, me exercito sozinha, mas ali é uma família, eu adquiri uma família tấo grande, que, quando a gente desiste assim, elas estão ali para incentivar (Participante E).

[...] eu gostei de tudo, muito feliz em conhecer todo o grupo, todas as colegas, a gente virou uma família, e isso é muito bom (Participante A).

As relaçóes humanas transformam; criam-se laços de afeto, carinho, empatia e apoio emocional, fundamentais para o processo do tratamento. Tais relaçóes, construídas no interior do grupo de dança, podem ser percebidas nesta fala:

Quando eu fiquei sozinha, eu me sentia depressiva, não conseguia falar com as pessoas, eu não queria sair, eu só queria ficar dentro do quarto... e agora não, eu já tenho contato com as pessoas, eu converso, acabou aquela angústia que eu tinha. Minha vontade era sempre de chorar e isso acabou, já não sinto mais, é só alegria, eu me sinto alegre, meu sono melhorou... (Participante D).

Ademais, o compartilhamento de momentos, as trocas estabelecidas com o que é comum às mulheres do grupo de dança, parece fazer do enfrentamento da doença um processo que pode tornar-se mais leve:

Formamos uma família e nos auxiliamos, vemos que nossas dificuldades são parecidas e isso ajuda a continuar (Participante C).

Outra fala complementar diz que:

Ali é uma família tão grande que eu adquiri; no grupo, quando a gente desiste assim ou desapega um pouco, ou até ficamos triste, eu continuo porque tenho todo o grupo ali para dar suporte. A gente fica mais animada, com mais vontade de fazer as coisas, é um incentivo muito grande (Participante E).

A Tabela 3 mostra que foi possível estabelecer relação entre os resultados quanti e qualitativos encontrados, no que diz respeito às variáveis analisadas.

\section{DISCUSSÃO}

O principal objetivo deste estudo foi investigar as percepçóes de otimismo e autoestima de mulheres em tratamento adjuvante de hormonioterapia do câncer de mama, por meio de intervençóes de dança do ventre. Após o período de intervenção, foi possível constatar que, das 14 mulheres que participaram, houve um aumento na autoestima no período pós-intervenção. Já nas cinco mulheres que participaram das duas entrevistas (pré e pós), os resultados quantitativos apresentaram uma discreta melhora. Entretanto, na comparação realizada entre discurso e quantificação, pôde-se perceber o resultado positivo em ambas as aferiçôes; ou seja, a complementação das abordagens quanti e quali para avaliar o impacto da intervenção.

Cabe destacar que os resultados desse segundo grupo (quali-quanti) foram muito expressivos e valiosos, uma vez que colocaram números, percepçóes, mesmo em uma amostra pequena. De acordo com os relatos, foi vivenciada uma experiência prazerosa e espontânea, de caráter lúdico e com importante estímulo físico e psicológico. Essas características percebidas contribuem para a percepção positiva da prática da dança do ventre, incidindo diretamente na autoestima como uma forma de divertida e motivadora para as mulheres. Esse aspecto vai ao encontro da definição de autoestima como sendo uma atitude positiva ou negativa em relação a si próprio, a soma 
Tabela 3. Relação dos resultados qualitativos e quantitativos das participantes

\begin{tabular}{|c|c|c|c|c|c|}
\hline \multirow[b]{2}{*}{ Variáveis } & \multicolumn{2}{|c|}{ Quantitativo } & \multicolumn{2}{|c|}{ Qualitativo } & \multirow[b]{2}{*}{ Valor de p } \\
\hline & $\begin{array}{c}\text { Período } \\
\text { Pré-intervenção } \\
\overline{\mathbf{x}} \text { (desvio-padrão) }\end{array}$ & $\begin{array}{c}\text { Período } \\
\text { pós-intervenção } \\
\overline{\mathbf{x}} \text { (desvio-padrão) }\end{array}$ & $\begin{array}{c}\text { Período } \\
\text { pré-intervenção }\end{array}$ & $\begin{array}{c}\text { Período } \\
\text { pós-intervenção }\end{array}$ & \\
\hline Autoestima & $32,0(1,8)$ & $36,6(4,0)$ & $\begin{array}{l}\text { Dor } \\
\text { Desconforto } \\
\text { Não olhar } \\
\text { para o corpo, } \\
\text { reconhecer o } \\
\text { corpo }\end{array}$ & $\begin{array}{l}\text { Aumento da } \\
\text { autoestima } \\
\text { Sentimento de } \\
\text { ser sexy } \\
\text { Gostar das } \\
\text { roupas } \\
\text { Sentir-se bem }\end{array}$ & $0,017^{*}$ \\
\hline Otimismo & $17,0(1,8)$ & $18,0(4,6)$ & $\begin{array}{c}\text { Arrasada } \\
\text { Mundo acabou } \\
\text { Desespero }\end{array}$ & $\begin{array}{l}\text { Recomeço } \\
\text { Liberdade } \\
\text { Esperança }\end{array}$ & $0,684^{* *}$ \\
\hline
\end{tabular}

$\left.{ }^{*}\right)$ Teste t pareado.

$\left.{ }^{(* *}\right)$ Teste de Wilcoxon.

de pensamentos e emoçóes de uma pessoa ao perceber o seu próprio valor pessoal ${ }^{13}$.

Em um estudo de 12 semanas, com amostra similar de 13 participantes no grupo intervenção e dez no grupo controle ${ }^{20}$, foi realizada uma série de exercícios adaptados para mulheres com câncer e mastectomizadas, tendo sido observado, com o questionário de Rosenberg, um aumento significativo de $8 \%$ na autoestima pós-intervençâo. Outros estudos apontam que o aumento da autoestima foi crucial na intervençáo psicológica diante dos sintomas de depressão das mulheres com câncer, repercutindo em aumento da qualidade de vida das pacientes, sugerindo que o otimismo foi vital para combater os mesmos sintomas ${ }^{21}$, impulsionando para o convívio social e oportunizando vínculos afetivos ${ }^{22}$.

Outrossim, a percepção de otimismo não variou positivamente em termos quantitativos, mas de forma qualitativa. Esse ponto pode ter relação direta com o entendimento da variável por parte das participantes e a forma como elas se apresentam de pessoa para pessoa; ou seja, é uma estratégia comportamental que permite aos indivíduos terem mais saúde física e mental, assim como o engajamento em atividades para sua manutenção ${ }^{23}$. O suporte social reduz os efeitos do estresse acometidos pela doença ${ }^{24}$, e, por sua vez, essa redução auxilia na promoção e em estratégias para seu enfrentamento. Ambas as variáveis, otimismo e suporte social, reduzem significativamente o sofrimento emocional do diagnóstico e do tratamento do câncer, bem como contribuem para um maior cuidado com a saúde ${ }^{25}$.

Foi considerado que pessoas otimistas acreditam que coisas boas aconteçam com elas, enquanto as pessimistas creem que coisas ruins ocorram ${ }^{26}$. Essa pequena diferença fundamenta o comportamento do indivíduo perante a doença, o tratamento e o futuro. Transitar entre confiança e força para os otimistas, com uma relação positiva e persistente em seus esforços, e descrença e derrotismo para os pessimistas, com expectativas negativas e limitantes, com maior desistência e menor obstinação ao tratamento, influencia a forma de lidar com as adversidades e o estresse $^{27}$. Na pessoa doente, é um processo difícil de trabalhar, principalmente quando esta possui uma doença crônica, como o câncer.

De acordo com Santos e Souza ${ }^{28}$, ao observar o processo do ponto psicossocial e não somente do processo da doença em si, é possível desenvolver programas e intervençóes não medicamentosas nesse âmbito, facilitando a troca de experiências. O suporte em grupo contribui para o enfrentamento ao câncer de mama, favorecendo o desenvolvimento pessoal dos participantes ${ }^{29}$.

\section{CONCLUSÃO}

As percepçôes das mulheres deste estudo, quanto aos períodos pré e pós-intervenção, revelaram-se positivas em relação à autoestima e ao otimismo. Enquanto na primeira suas evidências foram confirmadas qualitativa e quantitativamente, na segunda, apesar de a percepção ser positiva, o resultado náo se confirma na mesma proporção nos dados quantitativos, sugerindo uma melhora clínica discreta. $\mathrm{O}$ pequeno número de participantes mostra-se um fator limitante do estudo, evidenciando a necessidade de que pesquisas devam ser realizadas com grupos mais numerosos. A perda amostral pós-intervenção também é considerada um fator limitante, na medida em que representa uma maior dificuldade em alcançar a percepção geral do grupo de participantes. 


\section{CONTRIBUIÇÕES}

Todas as autoras contribuíram na concepção e/ou no planejamento do estudo; na obtenção, análise e interpretação dos dados; assim como na redação e revisão crítica; e aprovaram a versão final a ser publicada.

\section{DECLARAÇÃO DE CONFLITO DE INTERESSES}

Nada a declarar.

\section{FONTES DE FINANCIAMENTO}

Não há.

\section{REFERÊNCIAS}

1. Instituto Nacional de Câncer José Alencar Gomes da Silva. Estimativa 2020: incidência de câncer no Brasil. Rio de Janeiro: INCA; 2019.

2. Almeida TR, Guerra MR, Filgueira MST. Repercussóes do câncer de mama na imagem corporal da mulher: uma revisão sistemática. Physis.2012;22(3):1003-29. doi: http://doi.org/10.1590/s0103-73312012000300009

3. Bray F, Ferlay J, Soerjomataram I, et al. Global cancer statistics 2018: GLOBOCAN estimates of incidence and mortality worldwide for 36 cancers in 185 countries. CA Cancer J Clin. 2018;68(6):394-424. doi: https://doi. org/10.3322/caac. 21492

4. Almeida RA. Impacto da mastectomia na vida da mulher. Rev SBPH [Internet]. 2006 [acesso 2021 abr 8];9(2):99-113. Disponível em: http://pepsic. bvsalud.org/scielo.php?script=sci_abstract\&pid=S1516$08582006000200007 \& \operatorname{lng}=p t \& n r m=i s o \& t \operatorname{lng}=p t$

5. Simeão SFAP, Landro ICR, De Conti MHS, et al. Qualidade de vida em grupos de mulheres acometidas de câncer de mama. Ciênc Saúde Colet. 2013;18(3):779-88. doi: http://doi.org/10.1590/s141381232013000300024

6. Gomes NS, Silva SR. Avaliação da autoestima de mulheres submetidas a cirurgia de câncer de mama. Texto Contexto Enferm. 2013;22(2):509-16. doi: https://doi. org/10.1590/S0104-07072013000200029

7. Rossi L, Santos MA. Repercussôes psicológicas do adoecimento e tratamento em mulheres acometidas pelo câncer de mama. Psicol Cienc Prof. 2003;23(4):32-41. doi: https://doi.org/10.1590/ S1414-98932003000400006

8. Schultheisz TSV, Aprile MR. Autoestima, conceitos correlatos e avaliação. Rev Equilíbrio Corporal Saúde. 2013;5(1):36-48. doi: https://doi.org/10.17921/21769524.2013v5n1p\%25p

9. Ferreira MBLS. Estratégias de enfrentamento, resiliência e otimismo em mulheres no pós-tratamento do câncer de mama [dissertação]. Juiz de Fora (MG): Universidade Federal de Juiz de Fora; 2018.

10. Abrão ACP, Pedrão LJ. A contribuição da dança do ventre para a educação corporal, saúde física e mental de mulheres que frequentam uma academia de ginástica e dança. Rev Latino-Am Enferm. 2005;13(2):243-8. doi: http://doi.org/10.1590/S0104-11692005000200017

11. Minayo MCS, organizadora. Pesquisa social: teoria, método e criatividade. 21. ed. Petrópolis, RJ: Vozes, 1994.

12. Instituto Brasileiro de Geografía e Estatística. Síntese de indicadores sociais: uma análise das condições de vida da populaçâo brasileira 2018. Rio de Janeiro: IBGE; 2018. (Estudos e pesquisas. Informação demográfica e socioeconômica; n. 39)

13. Rosenberg M. Society and the adolescent self-image. Princeton: Princeton University Press; 1965.

14. Curbow B, Somerfield M. Use of the Rosenberg selfesteem scale with adult cancer patients. J Psychosoc Oncol. 9(2):113-31. doi: http://doi.org/10.1300/ J077v09n02_08

15. Dini GM, Quaresma MR, Ferreira LM. Adaptação cultural e validação da versão brasileira da escala de auto-estima de Rosenberg. Rev Bras Cir Plást. 2004;19(1):41-52.

16. Hutz CS, Zanon C. Revisão da apadtação, validação e normatização da escala de autoestima de Rosenberg. Aval Psicol [Internet]. 2011 Abr [acesso 2021 Abr 9];10(1):4149. Disponível em: http://pepsic.bvsalud.org/pdf/avp/ v10n1/v10n1a05.pdf

17. Bastianello MR, Hutz CS. Otimismo e suporte social em mulheres com câncer de mama: uma revisão sistemática. Psicol Teor Prat. 2016;18(2):19-33. doi: http://doi. org/10.15348/1980-6906/psicologia.v18n2p19-33

18. Boing L, Fretta TB, Vieira MCS, et al. Pilates and dance to patients with breast cancer undergoing treatment: study protocol for a randomized clinical trial MoveMama study. Trials. 2020;21(1):21-35. doi: http:// doi.org/10.1186/s13063-019-3874-6

19. Orlandi EP. Análise de discurso: princípios e procedimentos. 8. ed. Campinas, SP: Pontes; 2009.

20. Landry S, Chasles G, Pointreau Y, et al. Influence of an adapted physical activity program on self-esteem and quality of life of breast cancer patients after mastectomy. Oncology. 2018;95(3):188-91. doi: http:// doi.org/10.1159/000489265.

21. Ha EH, Cho YK. The mediating effects of self-esteem and optimism on the relationship between quality of life and depressive symptoms of breast cancer patients. Psychiatry Investig. 2014;11(4):437-45. doi: http://doi. org/10.4306/pi.2014.11.4.437

22. Dibbell-Hope S. The use of dance/movement therapy in psychological adaptation to breast cancer. Arts Psychother. 2000;27(1):51-68. doi: https://doi. org/10.1016/S0197-4556(99)00032-5 
23. Lopez SJ, Snyder CR, editors. Positive psychological assessment: a handbook of models and measures. Washington, DC: American Psychological Association; 2011.

24. Nurullah AS. Received and provided social support: a review of current evidence and future directions. Am J Health Studies. 2012;27(3):173-88.

25. Wimberly SR, Carver CS, Antoni MH. Effects of optimism, interpersonal relationships, and distress on psychosexual well-being among women with early stage breast cancer. Psychology Health. 2008;23(1):57-72. doi: http://doi.org/10.1080/14768320701204211

26. Carver CS, Scheier MF, Segerstrom SC. Optimism. Clin Psychol Rev. 2010;30(7):879-89. doi: http://doi. org/10.1016/j.cpr.2010.01.006

27. Carver CS, Connor-Smith J. Personality and coping. Annual Review Psychology. 2010;61(1):679-704. doi: http://doi.org/10.1146/annurev.psych.093008.100352

28. Santos MA, Souza C. Intervençóes grupais para mulheres com câncer de mama: desafios e possibilidades. Psic: Teor Pesqu. 2019;35:1-14. doi: http://doi. org/10.1590/0102.3772e 35410

29. Martins MM, Peres RS. Fatores terapêuticos em grupo de apoio a mulheres com câncer de mama. Psicologia, Saúde e Doenças. 2014;15(2):396-408. doi: http://doi. org/10.15309/14psd150206 